\title{
Two membrane proteins from Bifidobacterium breve UCC2003 constitute an ABC-type multidrug transporter
}

Correspondence

Abelardo Margolles

amargolles@ipla.csic.es

Received 26 April 2006

Revised 24 August 2006

Accepted 30 August 2006

\author{
Abelardo Margolles, ${ }^{1}$ Ana Belén Flórez, ${ }^{1}$ José Antonio Moreno, ${ }^{1,2}$ \\ Douwe van Sinderen ${ }^{2}$ and Clara G. de los Reyes-Gavilán ${ }^{1}$
}

\author{
${ }^{1}$ Instituto de Productos Lácteos de Asturias, Consejo Superior de Investigaciones Científicas \\ (CSIC), Ctra Infiesto s/n, 33300, Villaviciosa, Asturias, Spain \\ ${ }^{2}$ Department of Microbiology and Alimentary Pharmabiotic Centre, University College Cork, \\ Western Road, Cork, Ireland
}

\begin{abstract}
Intrinsic resistance to drugs is one of the main determining factors in bacterial survival in the intestinal ecosystem. This is mediated by, among others, multidrug resistance (MDR) transporters, membrane proteins which extrude noxious compounds with very different chemical structures and cellular targets. Two genes from Bifidobacterium breve encoding hypothetical membrane proteins with a high homology with members of the ATP-binding cassette (ABC) family of multidrug efflux transporters, were expressed separately and jointly in Lactococcus lactis. Cells co-expressing both proteins exhibited enhanced resistance levels to the antimicrobials nisin and polymyxin $B$.

Furthermore, the drug extrusion activity in membrane vesicles was increased when both proteins were co-expressed, compared to membranes in which the proteins were produced independently. Both proteins were co-purified from the membrane as a stable complex in a $1: 1$ ratio. This is believed to be the first study of a functional ABC-type multidrug transporter in Bifidobacterium and contributes to our understanding of the molecular mechanisms underlying the capacity of intestinal bacteria to tolerate cytotoxic compounds.
\end{abstract}

\section{INTRODUCTION}

Bifidobacteria are important members of the human gut microbiota, in which they can be present at concentrations as high as $10^{11}$ cells per $\mathrm{g}$ faeces, representing up to $91 \%$ of the total microbial population in breast-fed infants (Harmsen et al., 2000). Their presence has been associated with beneficial effects. On the basis of their role in promoting human wellbeing, some species and strains of the genus Bifidobacterium are considered to be probiotic and are used as active ingredients in functional foods, mainly dairy-based products (Ouwehand et al., 2002). Welldocumented clinically established applications of some strains of this genus are the treatment of diarrhoea and the balancing of the intestinal microbiota (Salminen \& Gueimonde, 2004), while other health-promoting actions, such as anticarcinogenic activity, immunomodulation and reduction of serum cholesterol levels, have been suggested (Isolauri et al., 2004). Bifidobacterium breve, one of the

Abbreviations: ABC, ATP-binding cassette; AMP-PNP, $5^{\prime}$-( $\beta, \gamma$-imido $)$ triphosphate; Bbm, Bifidobacterium breve multidrug transporter; DDM, $n$-dodecyl $\beta$-D-maltoside; MDR, multidrug resistance.

The GenBank/EMBL/DDBJ accession number for the sequence of the B. breve gene cluster is DQ486860. representative species of its genus, is among the predominant bacteria present in the gastrointestinal tract of infants (Matsuki et al., 1999).

Enteric bacteria have evolved to tolerate inhibitory factors in the intestinal niche. Their survival depends on tolerance to host-produced substances, such as bile (Begley et al., 2005; Yokota et al., 2000), and antimicrobial peptides (Ganzle et al., 1999; Mahida et al., 1997), but they are also conditioned by exposure to exogenous cytotoxic agents, including antibiotics (Vedantam \& Hecht, 2003). Nowadays, drug efflux, mediated by MultiDrug Resistance (MDR) transporters, is considered as one of the main mechanisms responsible for these resistances (Grkovic et al., 2002). These proteins can be subdivided into two groups according to structural and bioenergetic criteria. ATP-binding cassette (ABC) transporters power the transport via the hydrolysis of ATP, whereas the activity of secondary transporters is dependent on the transmembrane electrochemical gradient, typically the proton-motive force (Kim et al., 2004; Mazurkiewicz et al., 2005). Most of the bacterial multidrug efflux systems characterized up to now belong to the second class of transporters (Putman et al., 2000), and just a few of them, such as LmrA and LmrCD from Lactococcus lactis (Lubelski et al., 2004; van Veen et al., 1996), HorA from 
Lactobacillus brevis (Sakamoto et al., 2001), MsbA from Escherichia coli (Karow \& Georgopoulus, 1993), BmrA from Bacillus subtilis (Orelle et al., 2003) and EfrAB from Enterococcus faecalis (Lee et al., 2003), belong to the ABCtype family.

Recent evidence indicated that $B$. breve is more resistant to antibiotics than other Bifidobacterium species (Moubareck et al., 2005), suggesting that this species could have a stronger intrinsic resistance. In a previous study, we characterized $\mathrm{BbmR}$, a membrane protein from $B$. breve which was able to confer resistance to macrolides and exhibited characteristics reminiscent of MDR proteins (Margolles et al., 2005). Its homologue in Bifidobacterium longum, named Ctr, was also found to confer resistance to several antibiotics and to transport radioactive cholate (Price et al., 2006). The current study presents work relating to $B$. breve genes that play a role in its intrinsic resistance to cytotoxic compounds. We describe the gene cloning and functional characterization of a novel bifidobacterial $\mathrm{ABC}$ type multidrug transporter in L. lactis, which shares both structural and functional properties with prokaryotic and eukaryotic MDR proteins, being able to confer resistance to several antimicrobials and to transport cytotoxic drugs.

\section{METHODS}

Chemicals. DNase A, creatine phosphokinase, phosphocreatine, potassium EDTA, DTT, HEPES, adenosine $5^{\prime}$ - $(\beta, \gamma$-imido $)$ triphosphate
(AMP-PNP), chloramphenicol, erythromycin, nisin, polymyxin B, imidazole and $n$-dodecyl $\beta$-D-maltoside (DDM) were purchased from Sigma. Takara supplied all restriction enzymes, excluding $B s p L U 11$ (Roche Applied Science). Platinum- $P f x$ DNA polymerase and Hoechst-33342 [2'-(4-ethoxyphenyl)-5-(4-methyl-1-piperazinyl)-2,5'-bi-1 $H$-benzimidazole] were obtained from Invitrogen, and $\mathrm{Ni}^{2+}$ nitriloacetic acid (Ni-NTA) agarose was supplied by Qiagen. E-test strips were from AB Biodisk and ATP was from Amersham Biosciences. All chemicals were reagent grade and all solutions were made with molecular biology reagent water (Sigma).

Bacterial strains, plasmids, and culture conditions. Bacteria and plasmids used in this study are shown in Table 1. Bifdobacterium breve UCC2003 was grown at $37^{\circ} \mathrm{C}$ in MRS medium (Merck) supplemented with $0.05 \%(\mathrm{w} / \mathrm{v})$ L-cysteine in an anaerobic chamber (Mac500, Don Whitley Scientific). Lactococcus lactis subsp. lactis NZ9000 and NZ9700 (Kuipers et al., 1993, 1998) were cultivated at $30{ }^{\circ} \mathrm{C}$ in $\mathrm{M} 17$ broth (Oxoid) with $0.7 \%(\mathrm{w} / \mathrm{v})$ glucose (GM17) and $5 \mu \mathrm{g}$ chloramphenicol or $5 \mu \mathrm{g}$ erythromycin $\mathrm{ml}^{-1}$ when they contained pNZ8048 and its derivatives or pNZE8048 and its derivatives respectively. Cells cotransformed with pNAbcA (or $\mathrm{pNHAbcA}$ ) and $\mathrm{pNAbcB}$ were grown under the same conditions, but in a medium that contained $3 \mu \mathrm{g}$ chloramphenicol plus $3 \mu \mathrm{g}$ erythromycin $\mathrm{ml}^{-1}$.

DNA and RNA manipulation, cloning of the genes, and sequence analysis. DNA manipulations were carried out as described by Sambrook et al. (1989). Total DNA was obtained from B. breve as previously described (Margolles \& de los Reyes-Gavilán, 2003). Vector pNZE8048 was constructed by amplifying a DNA fragment from the vector pNG8048 (Zúñiga et al., 2002), with the primers emr-f and emr-r (Table 1). The resulting PCR product was

Table 1. Bacterial strains, plasmids and primers

\begin{tabular}{|c|c|c|}
\hline Strain or plasmid & Relevant phenotype or genotype & Source or reference \\
\hline B. breve UCC2003 & Infant isolate & MacConaill et al. (2003) \\
\hline L. lactis NZ9000 & L. lactis MG1363 pepN:: nisRK & Kuipers et al. (1998) \\
\hline L. lactis NZ9700 & Nisin-producing strain & Kuipers et al. (1993) \\
\hline pNZ8048 & Gene expression vector, $\mathrm{P}_{n i s A}, \mathrm{Cm}^{\mathrm{r}}$ & de Ruyter et al. (1996) \\
\hline pNZE8048 & Gene expression vector, $\mathrm{P}_{\text {nisA }}, \mathrm{Em}^{\mathrm{r}}$ & This work \\
\hline pNAbcA & pNZE8048 derivative; $a b c A$ & This work \\
\hline pNAbcB & pNZ8048 derivative; $a b c B$ & This work \\
\hline pNHAbcA & pNZE8048 derivative; His-tag $a b c A$ & This work \\
\hline Primer & Sequence ${ }^{*}$ & \\
\hline$e m r-\mathrm{f}$ & 5'-AAGGCCAGGAAGATCTCCGATTCACAAAAAATAGGCACACG-3' & This work \\
\hline$e m r-\mathrm{r}$ & 5'-CGATATCGGATCCGTCGACCCGTGC-3' & This work \\
\hline$a b c A-\mathrm{f}$ & 5'-TGCGATCACATGTACGTCGATCCGGGAATCAATACCAGCGC-3' & This work \\
\hline$a b c A-\mathrm{r}$ & 5'-ATACGGAGAATTCTTATTAAAACCCCTGTGCGGCGCC-3' & This work \\
\hline$a b c B-f$ & 5'-TGCGACCACCATGGCACAACGCAATACATTTCGCG-3' & This work \\
\hline$a b c B-\mathrm{r}$ & 5'-GCCGACTCTAGATTACTACTCAGTAGCCCCGGTGG-3' & This work \\
\hline$a b c A h-\mathrm{f}$ & 5'-GCTGTATCAAGATTCGCAAGCTGC-3' & This work \\
\hline$a b c A h-\mathrm{r}$ & $\begin{array}{l}\text { 5'-TGCGATCAGAATTCTTATTAGTGATGGTGATGGTGATGAAAC- } \\
\text { CCCTGTGCGGCG CCGGACTGG-3' }\end{array}$ & This work \\
\hline$a b c A-f q$ & 5'-ACGACTGGCAGCGATTCAAC-3' & This work \\
\hline$a b c A-r q$ & 5'-GACCTGCTCGACGATTGTGA-3' & This work \\
\hline$a b c B-\mathrm{fq}$ & 5'-TTCTCCGACATCTTCACATTCTTC-3' & This work \\
\hline$a b c B$-rq & 5'-CAGTACGAGGCTCCACAATGC-3' & This work \\
\hline
\end{tabular}

${ }^{*}$ Restriction sites are underlined and the codons for the histidine tag are in bold italic. 
digested with SalI and BglII, and ligated with SalI/BglII-digested pNZ8048, yielding pNZE8048, in which the chloramphenicol resistance marker is replaced by an erythromycin resistance cassette.

The structural genes $a b c A$ and $a b c B$ were amplified from the genome of $B$. breve by PCR using primers $a b c A-f$ and $a b c A-r$ (for gene $a b c A$ ), and $a b c B$-f and $a b c B-\mathrm{r}$ (for gene $a b c B$ ) (Table 1), respectively. Given that the $a b c A$ gene contains an internal NcoI site, the enzyme BspLU11I, which yields compatible ends with $\mathrm{NcoI}$, was used in the cloning procedure. The $a b c A$ gene was amplified, digested with $B s p L U 11 \mathrm{I}$ and EcoRI, and ligated into pNZE8048, previously treated with $N c o$ I and $E c o$ RI, yielding pNAbcA. For $a b c B$, the amplicon was digested with $N c o I$ and $X b a \mathrm{I}$, and ligated with $N c o \mathrm{I} / \mathrm{XbaI}$-digested pNZ8048, resulting in pNAbcB. Furthermore, in order to introduce a hexahistidine tag at the C-terminus of AbcA, a fragment of $a b c A$ was amplified using the primers $a b c A h$-f and $a b c A h-\mathrm{r}$ (Table 1), digested with $C l a I$ and EcoRI, and ligated into pNAbcA, previously cut with the same enzymes. This construction yielded plasmid pNHAbcA. The vectors $\mathrm{pNAbcA}$ and $\mathrm{pNAbcB}$ were transformed into electrocompetent L. lactis NZ9000 cells using previously described methods (de Ruyter et al., 1996), and transformants were screened by restriction analysis of the recovered plasmids. For co-expression of $\mathrm{AbcA}$ and $\mathrm{AbcB}, \mathrm{pNAbcA}$ (or pNHAbcA) was introduced into electrocompetent NZ9000 cells containing pNAbcB. To confirm that no PCR-borne mutations were introduced, the fidelity of the inserts was verified by DNA sequencing of both strands with an ABI Prism 377 sequencer (Applied Biosystems).

Real-time PCR was used to assess the expression levels of $a b c A$ and $a b c B$. Primers $a b c A-\mathrm{fq}, a b c A-\mathrm{rq}, a b c B$-fq and $a b c B$-rq were chosen to amplify internal fragments of 128 and $84 \mathrm{bp}$ of $a b c A$ and $a b c B$, respectively (Table 1 ). Four independent cultures of $L$. lactis cells were disrupted with glass beads $(0 \cdot 5 \mu \mathrm{m})$ in a FastPrep FP120 Instrument (Thermo Savant). Total RNA was extracted using Tri-Reagent solution according to the manufacturer's instructions (Sigma). Two micrograms of total RNA was treated with 2 units of DNase (Fermentas) for $1 \mathrm{~h}$ at $37^{\circ} \mathrm{C}$. Then, cDNA was synthesized using the iScript cDNA synthesis kit (Bio-Rad). Absence of chromosomal DNA contamination was checked by real-time PCR. Real-time PCR reactions were carried out using an ABI PRISM 7500 with a SYBR green PCR master mix (Applied Biosystems). The efficiency was calculated based on the slope of a standard curve. In all cases, the $16 \mathrm{~S}$ rRNA level was used as an internal control.

The stability of pNAbcA and pNAbcB co-existing in the same cell was checked by growing the cells for more than 70 generations in GM17 broth containing chloramphenicol and erythromycin (five consecutive cultures inoculated with $0.0037 \%(\mathrm{v} / \mathrm{v})$ of a culture grown to an $\mathrm{OD}_{600}$ of about $1 \cdot 2$ ). In parallel, cells were plated on GM17 agar with and without antibiotics, to confirm that all cells contained the two antibiotic markers. Subsequently, 24 independent colonies ( 12 colonies from plates inoculated with cultures grown for 42 generations, and 12 colonies from plates inoculated with cultures grown for 71 generations) were analysed, and plasmids were extracted with the GenElute DNA kit (Sigma) and digested with BglII to verify that no DNA recombination had occurred. Furthermore, the genes $a b c A$ and $a b c B$, and the upstream region corresponding to the nisin promoter in $\mathrm{pNAbcA}$ and $\mathrm{pNAbcB}$, were sequenced after the five consecutive cultures to confirm that no mutations were produced during growth under selective pressure when both plasmids are present in the same cell.

DNA and protein sequences were analysed using the computer program Clone Manager 5 (Scientific and Educational Software). Homology searches and multiple sequence alignments (clustalw) were carried out using the BLAST server of the National Center for Biotechnology Information (http://www.ncbi.nlm.nih.gov) and the software available on the Web page of the Pôle-Bioinformatique Lyonnais (http://pbil.univ-lyon1.fr/). The Neural Network Promoter
Prediction Software (http://www.fruitfly.org/seq_tools/) was used for searching putative promoter regions. Homology trees were constructed with the TreeTop-Phylogenetic Prediction program (http://www. genebee.msu.su/).

Preparation of inside-out membrane vesicles. For the isolation of inside-out membrane vesicles of L. lactis NZ9000, cells were grown at $30{ }^{\circ} \mathrm{C}$ to an $\mathrm{OD}_{600}$ of about $0 \cdot 4$. At this point, $0 \cdot 1 \%(\mathrm{v} / \mathrm{v})$ of the supernatant of the nisin-producing L. lactis strain NZ9700 was added to the culture to trigger transcription of the $a b c A$ or $a b c B$ gene, or jointly the $a b c A / a b c B$ genes from the nis $A$ promoter. Subsequently, the cells were incubated for $1 \mathrm{~h}$ at $30{ }^{\circ} \mathrm{C}$, harvested at an $\mathrm{OD}_{600}$ of approximately 0.8 by centrifugation, and membrane vesicles were obtained as previously described (Margolles et al., 1999). The membrane vesicles were stored in small aliquots in liquid nitrogen.

Antimicrobial susceptibility testing. Cells were grown at $30^{\circ} \mathrm{C}$ to an $\mathrm{OD}_{600}$ of about 0.4 in GM17 broth containing chloramphenicol or erythromycin, or both. To induce gene expression at this point, $0 \cdot 1 \%(\mathrm{v} / \mathrm{v})$ of the culture supernatant of L. lactis NZ9700 was added to the GM17 broth. Subsequently, the cells were incubated for $1 \mathrm{~h}$. For MIC determinations, $1 \mathrm{ml}$ of the culture was added to $30 \mathrm{ml}$ soft $\left(0 \cdot 7 \%\right.$ agar) GM17 at $40{ }^{\circ} \mathrm{C}$, containing $0 \cdot 1 \%$ of the $L$. lactis NZ9700 culture supernatant. Then, the mixture was layered on the top of $15 \mathrm{~cm}$ Petri dishes containing $50 \mathrm{ml} \mathrm{GM17} \mathrm{(2 \%} \mathrm{agar),} \mathrm{to}$ which supernatant of the L. lactis nisin-producing strain had been added. E-test strips of 15 different antibiotics were applied with an applicator, and MICs were determined after $24 \mathrm{~h}$ incubation. For resistance assays on agar media, cultures were centrifuged, resuspended in GM17 broth and the $\mathrm{OD}_{600}$ was adjusted to 1 . Then, serial 10 -fold dilutions were performed, and $5 \mu \mathrm{l}$ of each dilution was spotted on the GM17 agar medium with or without the inhibitory agent (nisin or polymyxin B). The plates were incubated for $24 \mathrm{~h}$ and all the experiments were done at least in triplicate.

Hoechst-33342 transport in membrane vesicles. Inside-out membrane vesicles ( $1 \mathrm{mg}$ of total membrane protein) were diluted in $2 \mathrm{ml}$ ATP regenerating buffer $(50 \mathrm{mM}$ potassium HEPES buffer, pH 7.1, containing $5 \mathrm{mM} \mathrm{MgSO} 4,8.5 \mathrm{mM} \mathrm{NaCl}, 0 \cdot 1 \mathrm{mg}$ creatine kinase $\mathrm{ml}^{-1}$ and $5 \mathrm{mM}$ phosphocreatine) in a $3 \mathrm{ml}$ quartz cuvette. After 1 min incubation at $30^{\circ} \mathrm{C}$, Hoechst- 33342 was added to a final concentration of $0 \cdot 2 \mu \mathrm{M}$. Once the signal was stable, $\mathrm{Mg}^{2+}$-ATP or $\mathrm{Mg}^{2+}$-AMP-PNP was added to a final concentration of $2 \mathrm{mM}$, and the fluorescence intensity (excitation $355 \mathrm{~nm}$, emission $457 \mathrm{~nm}$ ) was followed with an Eclipse fluorescence spectrophotometer (Varian) provided with a magnetically stirred holder at $30^{\circ} \mathrm{C}$.

Affinity purification and identification of the purified proteins. Inside-out membrane vesicles from $L$. lactis NZ9000 containing $\mathrm{pNHAbcA} / \mathrm{pNAbcB}\left(12 \mathrm{mg}\right.$ total membrane protein $\left.\mathrm{ml}^{-1}\right)$ were solubilized in $50 \mathrm{mM}$ potassium phosphate buffer, $\mathrm{pH} 8 \cdot 0$, containing $10 \%(\mathrm{v} / \mathrm{v})$ glycerol, $100 \mathrm{mM} \mathrm{NaCl}$ and $1 \%(\mathrm{w} / \mathrm{v})$ DDM. The suspension was mixed and, after $30 \mathrm{~min}$ incubation at $4{ }^{\circ} \mathrm{C}$, the insoluble material was removed by centrifugation $(250000 \mathrm{~g}$, $20 \mathrm{~min}, 4^{\circ} \mathrm{C}$ ). For purification of histidine-tagged AbcA, $1 \mathrm{ml}$ solubilized membrane proteins was mixed and incubated for $1 \mathrm{~h}$ with $200 \mu \mathrm{l} \mathrm{Ni-NTA}$ agarose, which was preequilibrated in buffer A [50 mM potassium phosphate, $\mathrm{pH} 8 \cdot 0,100 \mathrm{mM} \mathrm{NaCl}, 10 \%(\mathrm{v} / \mathrm{v})$ glycerol, $0 \cdot 05 \%(\mathrm{w} / \mathrm{v}) \mathrm{DDM}$ ] plus $10 \mathrm{mM}$ imidazole. After incubation, the resin was transferred to a Bio-spin column (Bio-Rad) and washed first with 25 column volumes of buffer A containing $10 \mathrm{mM}$ imidazole, and subsequently with 12 column volumes of buffer A ( $\mathrm{pH} 7 \cdot 0$ ) containing $30 \mathrm{mM}$ imidazole. The protein was eluted with buffer A, pH 7·0, supplemented with $250 \mathrm{mM}$ imidazole. All steps were carried out at $4{ }^{\circ} \mathrm{C}$.

Proteins from the membrane and eluted fractions were checked by SDS-PAGE by using a Mini-Protean II system (Bio-Rad). SDS-PAGE 
gels were stained with Coomassie BioSafe (Bio-Rad), and densitometric scanning was carried out by using the Gel Doc 2000 system with the Quantity One software (Bio-Rad). For protein identification, bands were excised from gels and submitted to tryptic digestion, and mass spectrometry analyses were performed at the Servicio de Proteómica of the Centro Nacional de Investigaciones Cardiovasculares. All protein concentrations were determined by the Lowry method.

\section{RESULTS AND DISCUSSION}

\section{Identification and sequence analysis of $a b c A$ and $a b c B$}

A 7930 bp DNA fragment was selected from the preliminary genome sequence of B. breve UCC2003 (S. Leahy, J. A. Moreno, M. O'Connell-Motherway, H. G. Higgins, G. F. Fitzgerald \& D. Van Sinderen, unpublished data). Its genetic analysis revealed the presence of two adjacent ORFs displaying significant homology to several hypothetical MDR transporters, named $a b c A$ and $a b c B$, putatively transcribed in the same direction and separated by $202 \mathrm{bp}$. A putative promoter sequence was found $182 \mathrm{bp}$ upstream of the potential $a b c A$ start codon, but not upstream of the $a b c B$ gene. The first gene, $a b c A$, possesses a putative ribosome-binding site $8 \mathrm{bp}$ upstream of its start codon (GGTGAT), while the second gene, $a b c B$, is followed by a transcription terminator-like (inverted repeat) sequence (Fig. 1a). The $a b c A$ and $a b c B$ genes are predicted to encode 636 and 601 aa proteins, respectively, identified by a database enquiry (BLASTP) as putative ABC transporters. Hydropathy profile analysis using the Expasy Proteomic Server predicted that both proteins possess a transmembrane domain, composed of six putative transmembrane helices, followed by a hydrophilic portion with a putative ATP-binding domain, containing the Walker A and Walker $\mathrm{B}$ motifs, and the $\mathrm{ABC}$ signature sequence (Schneider \& Hunke, 1998; Walker et al., 1982) (Fig. 1b). Since the ABC domain is highly conserved, in order to determine evolutionary relationships with other transporters the predicted permease domains of AbcA (339 Nterminal amino acids) and $\mathrm{AbcB}(347 \mathrm{~N}$-terminal amino acids) were subjected to BLASTP analysis and compared with homologous sequences. Analysis of a multiple alignment of the primary sequence of these domains showed that they are closely related to a number of $\mathrm{ABC}$ transporters from bacteria (Fig. 1c, d). Both protein $\mathrm{A}$ and $\mathrm{B}$ domains displayed the highest homology scores with proteins that were located in tandem on the genomes. Interestingly, the AbcA permease domain matched with proteins encoded by the upstream genes, whereas the $A b c B$ permease domain matched with proteins encoded by the downstream genes of the tandem-like structures. These results indicated that $\mathrm{AbcA} / \mathrm{AbcB}$ homologues are widely distributed in bacteria, and most likely they are orthologous systems performing similar physiological functions. This prompted us to study the functionality of both proteins (independently or together) by investigating phenotypic changes of a cell that expresses these proteins, as well as determining their role in multidrug resistance and their ability to transport drugs.

\section{Production of the $A B C$ transporters and antimicrobial activity profiles}

In recent years, molecular techniques for disrupting genes and controlling gene expression have been extensively used to functionally study MDR transporters (Doerrler \& Raetz, 2002; Hirata et al., 2004; Lubelski et al., 2004; Ravaud et al., 2006). However, the lack of efficient transformation systems and the paucity of effective molecular tools (e.g. cloning and expression vectors and gene inactivation systems) have so far severely limited functional studies in Bifidobacterium (Ventura et al., 2004). Since previous studies from our group have shown that the nisin-inducible system from the Gram-positive bacterium L. lactis can generate large quantities of bifidobacterial membrane and cytosolic proteins (Margolles \& de los Reyes-Gavilán, 2003; Margolles et al., 2005), we selected this bacterium as the host to produce $\mathrm{AbcA}$ and $\mathrm{AbcB}$. We cloned (independently or together) $a b c A$ and $a b c B$ by constructing plasmids pNAbcA and pNAbcB, which were then introduced into $L$. lactis cells. Both plasmids could be maintained in the same host cell after more than 70 generations. Total cell counts indicated that all cells contained the two antibiotic markers, and no recombinations or mutations were observed after sequencing and restriction enzyme analysis of the plasmids in any of the tested colonies. This proves that pNAbcA and pNAbcB could co-exist and are stable in the same cell, and shows that they did not segregate and were not maintained in different cell subpopulations.

Gene expression and protein synthesis were investigated by real-time PCR and SDS-PAGE. Only the expression of AbcB was apparent on the protein electrophoresis profiles, probably due to the coincidence of the molecular mass of AbcA with one of the major membrane proteins of L. lactis (Fig. 2). However, real-time PCR showed that both $a b c A$ and $a b c B$ were transcribed, either when the genes were cloned separately or together. Interestingly, in cells carrying both pNAbcA and $\mathrm{pNAbcB}$, the $a b c B$ transcript appears to be about two times more abundant than the $a b c A$ transcript $\left(2^{\Delta \Delta \mathrm{CT}}=2^{1 \cdot 04 \pm 0 \cdot 059}\right)$, whereas when $a b c A$ and $a b c B$ were expressed alone, their transcripts were $2^{2 \cdot 43 \pm 1 \cdot 17}$ times and $2^{1.49 \pm 1.52}$ times more abundant, respectively, than the corresponding transcripts of the cells containing both plasmids.

We investigated if $\mathrm{AbcA}$ and $\mathrm{AbcB}$ could be involved in conferring antimicrobial resistance. We determined the MIC of 15 antibiotics using E-test strips, a quantitative method that has emerged in the last few years as an accurate alternative to the traditional methods, such as microdilution and disk diffusion (Turnbull et al., 2004). The antibiotics tested were ampicillin, benzylpenicillin, clindamycin, ciprofloxacin, doxycycline, kanamycin, meropenem, minocycline, polymyxin, quinupristin-dalfopristin, rifampicin (low range, 0.002 to $32 \mu \mathrm{g} \mathrm{ml}^{-1}$ ), streptomycin (high range, 
Putative promoter sequence

TGGGCTGTTGCGATTGGACGCAAGCCGCCTAGACTAGTACGCGTTTACGA
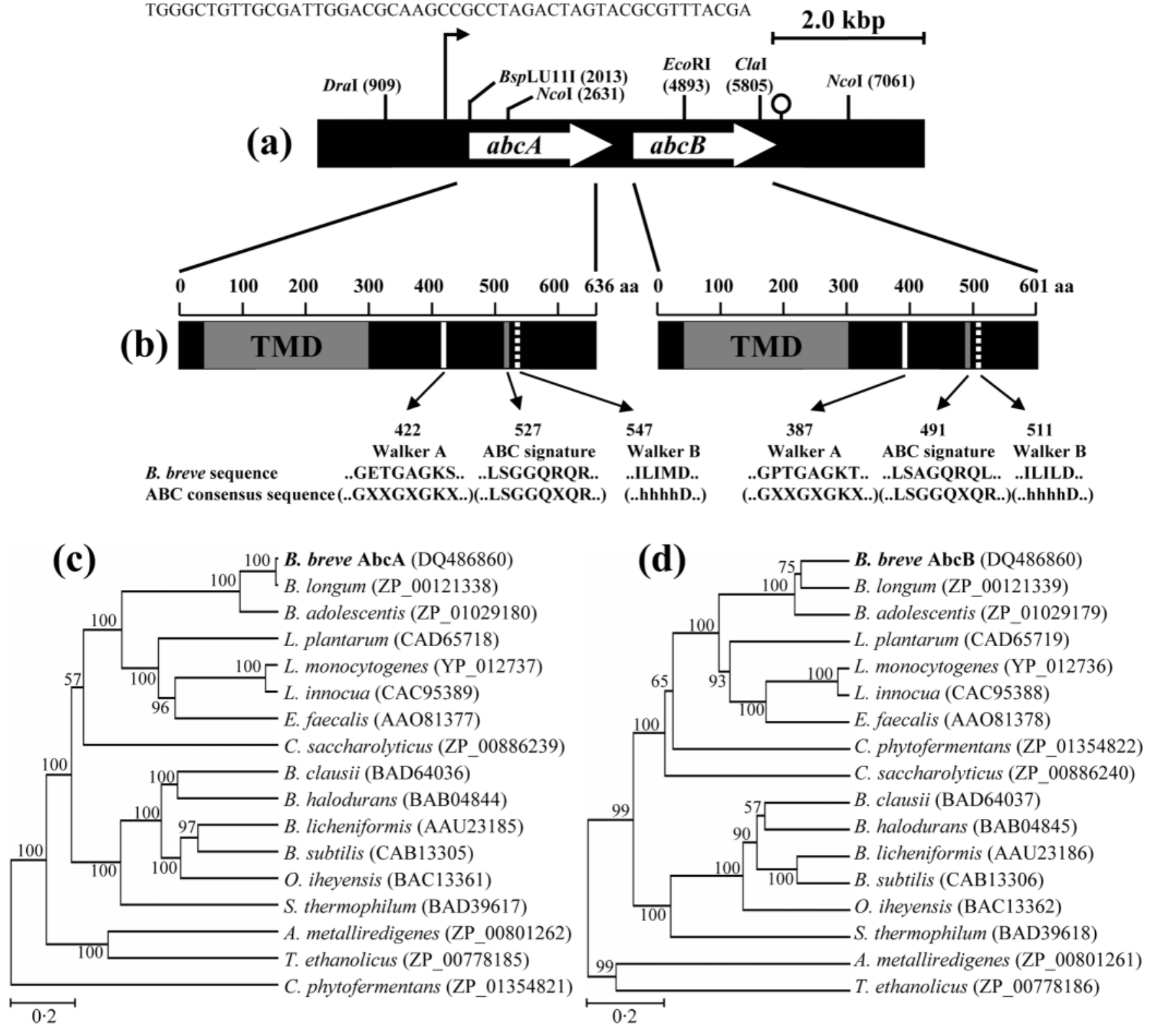

Fig. 1. (a) Organization of the $B$. breve UCC2003 genomic region containing the $a b c A$ and $a b c B$ genes. The white arrows indicate the relative positions and direction of transcription of the ORFs. The pin-like symbol indicates a terminator-like sequence. Relevant restriction sites and their locations in the sequence are also indicated. A putative promoter region is indicated with a black arrow upstream of $a b c A$. (b) Modular structure of $A b c A$ and $A b c B$. The amino acid sequences in parentheses are the consensus sequences of the $A B C$ transporter family. TMD, transmembrane domain; $X$, any amino acid; $h$, hydrophobic residue. (c, d) Phylogenetic relationship analysis of the permease domains of AbcA (c) and AbcB (d). Database accession numbers are given in parentheses. Trees were constructed with the matrix of pair distances between sequences using the cluster algorithm, and bootstrap values (100 replicates) are given at the branch points.

$0 \cdot 064$ to $\left.1,024 \mu \mathrm{g} \mathrm{ml}^{-1}\right)$, tetracycline, trimethoprim-sulfamethoxazole, and vancomycin. Chloramphenicol and macrolides were not tested since they are the selection markers in the vectors. A small increase in resistance was observed for ciprofloxacin. The MICs for the control strain, harbouring the empty plasmid, and the strain harbouring pNAbcA were $3 \cdot 3 \pm 0 \cdot 6 \mu \mathrm{g} \mathrm{ml}^{-1}$, whereas those for cells containing $\mathrm{pNAbcB}$ or $\mathrm{pNAbcA} / \mathrm{pNAbcB}$ were $6 \cdot 0 \pm 0$ and $6 \cdot 7 \pm 1 \cdot 2 \mu \mathrm{g} \mathrm{ml}^{-1}$, respectively. Interestingly, a recent report demonstrated that the increased expression of two multidrug $\mathrm{ABC}$ transporter-like genes is associated with ethidium bromide and ciprofloxacin resistance in Mycoplasma hominis (Raherison et al., 2005). In our case, the most significant changes were found for polymyxin B, 


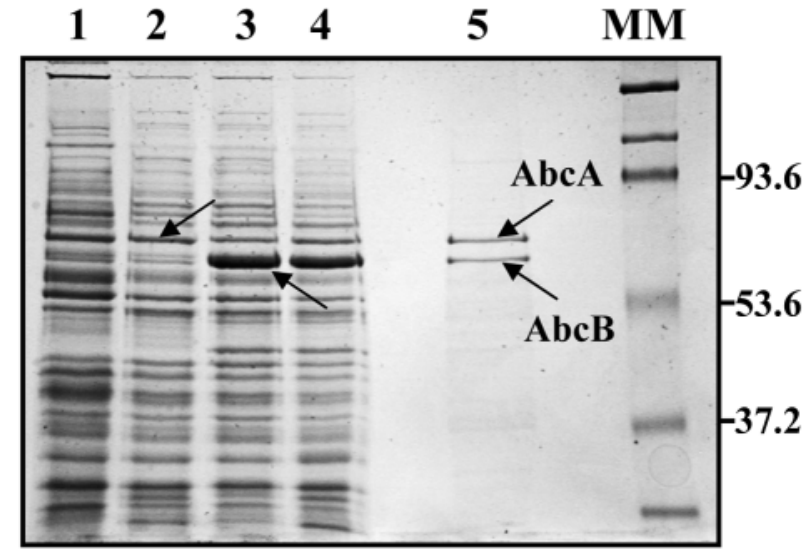

Fig. 2. Expression of $A b c A$ and $A b c B$ and co-purification of the $A b c A / A b c B$ complex. Coomassie BioSafe-stained SDSPAGE gel of inside-out membrane vesicles (30 $\mu \mathrm{g}$ protein/lane) from cells harbouring the empty vector ( $p N Z 8048$, lane 1) or cells expressing AbcA (pNAbcA, lane 2), AbcB (pNAbcB, lane 3 ), or jointly $A b c A$ and $A b c B$ (pNAbcA/pNAbcB, lane 4). The purified histidine-tagged $A b c A$ from a Ni-NTA column with $250 \mathrm{mM}$ imidazole and the co-eluted protein $\mathrm{AbcB}$ are represented in lane 5. MM, protein markers (molecular masses in $\mathrm{kDa}$ are indicated on the right). The arrows indicate the positions of $\mathrm{AbcA}$ and $\mathrm{AbcB}$.

the resistance increasing more than fourfold for cells expressing AbcA (MIC $42 \cdot 7 \pm 9 \cdot 2 \mu \mathrm{g} \mathrm{ml}^{-1}$, compared to $9 \cdot 3 \pm 2 \cdot 3$ for the control strain), and more than twelve-fold for cells expressing $\mathrm{AbcB}\left(128 \cdot 0 \pm 0 \mu \mathrm{g} \mathrm{ml}^{-1}\right)$ or both proteins $\left(149 \cdot 3 \pm 40 \mu \mathrm{g} \mathrm{ml}^{-1}\right)$. No significant differences between the control strain and the membrane-proteinexpressing cells were found for any other antibiotic using the E-test assay.

Since polymyxin B is a polycationic antimicrobial peptide that acts at the cell surface level, dissipating proton-motive force by making pores in the cell membrane (Hancock \& Chapple, 1999), we decided to investigate the resistanceconferring capability of $\mathrm{AbcA}$ and $\mathrm{AbcB}$ to the antimicrobial peptide nisin. Therefore, susceptibility differences against nisin and polymyxin $\mathrm{B}$ between L. lactis cells harbouring pNAbcA, pNAbcB or $\mathrm{pNAbcA} / \mathrm{pNAbcB}$, and bacterial cells harbouring the control plasmid, were determined in GM17 agar. The joint expression of $\mathrm{AbcA}$ and $\mathrm{AbcB}$ resulted in an increased resistance to nisin and polymyxin with respect to the control, which became apparent by colony formation at the highest dilution used. However, considerable nisin resistance was also found under similar conditions for cells expressing only $\mathrm{AbcB}$ (Fig. 3). This indicated that the expression of $\mathrm{AbcB}$ alone could also reduce the cell susceptibility to nisin, although to a lesser extent than when both proteins are co-expressed. Consistent with the above finding, it has previously been shown that certain $\mathrm{ABC}$ transporters can act on bacteriocin-like compounds. For example, the ABC-transporter LmrB from L. lactis confers resistance to LsbA and LsbB, two class II bacteriocins (Gajic et al., 2003). It does so, most likely, by removing LsbA and LsbB from the cytoplasmic membrane, which is the target of these antimicrobial peptides. Other studies have suggested that $\mathrm{ABC}$ transporters could play a key role in generating resistance to nisin and other antimicrobial peptides in Gram-positive bacteria (Kok et al., 2005).

\section{Transport of Hoechst-33342 in membrane vesicles}

Hoechst-33342 is a cytotoxic drug extensively employed to detect the activity of MDR transporters (Lubelski et al., 2004; Margolles et al., 1999; Sakamoto et al., 2001; van Veen et al., 2000; Woebking et al., 2005). This probe has the property of being fluorescent when present in the lipid environment of biomembranes, while being essentially nonfluorescent in the aqueous phase (Shapiro \& Ling, 1995). Since MDR transporters are thought to pump out hydrophobic drugs from (or close to) the cytoplasmic membrane (Putman et al., 2000), this compound was used to study the extrusion of drugs directly from the membrane to the aqueous phase, via the decrease of fluorescence observed when extrusion activity is present (Margolles et al., 1999; Shapiro \& Ling, 1995; Woebking et al., 2005). Furthermore, the advantage of carrying out functional

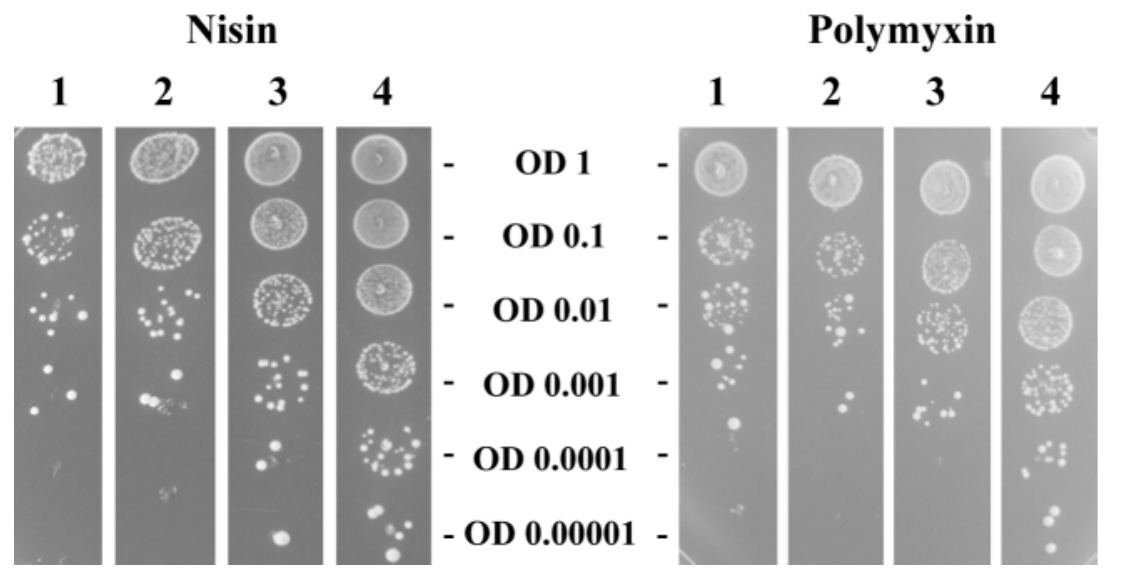

Fig. 3. Effect of $A b c A, A b c B$, and $A b c A /$ AbcB expression on the susceptibility of $L$. lactis to nisin and polymyxin. Results shown are from cells harbouring pNZ8048 (1), pNAbcA (2), pNAbcB (3), or pNAbcA and pNAbcB (4) and spotted on GM17 plates containing $78 \mathrm{ng}$ nisin $\mathrm{ml}^{-1}$ or $62 \mu \mathrm{g}$ polymyxin $\mathrm{B} \mathrm{ml}^{-1}$. 
studies in isolated membranes is the avoidance of possible interference caused by other cellular components that may modify the transport activity. Experiments performed in inside-out membrane vesicles of L. lactis NZ9000 cells showed the highest transport rate of Hoechst-33342 in membranes harbouring $\mathrm{AbcA}$ and $\mathrm{AbcB}$, although significant transport was also detected in AbcB-containing membrane vesicles. AbcA-containing membranes displayed an extremely low transport activity as compared to the other two membrane systems (Fig. 4). In addition, the ATPdependency of the transport process was demonstrated, since no activity was detected in the presence of the nonhydrolysable ATP analogue AMP-PNP. ATP-dependent transport of Hoechst-33342 was not observed in control membrane vesicles.

\section{$A b c A$ and $A b c B$ form a stable complex in the membrane}

The results of the experiments described above point to cooperation between $\mathrm{AbcA}$ and $\mathrm{AbcB}$ that results in an increased resistance to nisin and polymyxin, and an enhanced ability to extrude Hoechst-33342 from the membrane of $L$. lactis. As suggested for other $\mathrm{ABC}$ transporters (Abele \& Tampe, 1999; Lee et al., 2003; Lubelski et al., 2004), this is likely to happen through a direct interaction of $\mathrm{AbcA}$ and $\mathrm{AbcB}$ in the membrane, where these two proteins are assumed to form a complex that represents the functional unit of the transporter. To prove this assumption for the $\mathrm{AbcAB}$ proteins, a histidine tag was attached to the C-terminal part of AbcA to facilitate purification of the complex by affinity chromatography. For this purpose, membranes were isolated from cells harbouring $\mathrm{pNHAbcA} / \mathrm{pNAbcB}$, solubilized with a DDM-containing buffer and subjected to a single-step Ni-NTA affinity purification procedure (Fig. 2). When His-tagged AbcA was purified, two protein bands were eluted, with molecular masses that correspond to $\mathrm{AbcA}$ and $\mathrm{AbcB}$. The identity of the proteins was confirmed by mass spectrometry, the upper band being identified as AbcA, and the lower as AbcB. Purified proteins were analysed by densitometry of Coomassie BioSafe-stained SDS-PAGE gels, showing that both proteins are present in approximately equal amounts, indicating the existence of a stable membrane-associated complex with a stoichiometry of $1: 1$ (Fig. 2).

It has been experimentally proved that several prokaryotic ABC transporters act as dimers. Homodimerization has been demonstrated for LmrA of L. lactis (van Veen et al., 2000), MsbA of E. coli (Chang \& Roth, 2001) and BmrA of B. subtilis (Ravaud et al., 2006), while a heterodimeric complex was found to be the functional unit of the MDR transporter LmrCD from L. lactis (Lubelski et al., 2004). However, in our study we have found that $\mathrm{AbcB}$ can retain some activity by itself, conferring nisin resistance and extruding Hoechst33342 from the membrane, although to a lesser extent than when both proteins are present. A similar effect has also been reported for other $\mathrm{ABC}$ transporters. In eukaryotic cells, the mammalian proteins ADLP (adrenoleukodystrophy protein), ALDRP (adrenoleukodystrophy-related protein) and PMP70 (70 kDa peroxisomal protein) were found to act as homo- as well as heterodimers, and it was proposed that the different dimer combinations vary in activity and substrate specificity (Liu et al., 1999). Genetic evidence suggests that the substrate specificity of the traffic ATPase transporters involved in the uptake of eye pigment precursors in Drosophila melanogaster (the white, scarlet and brown gene products) depends on the dimer formed: white and scarlet together form a tryptophan transporter, while the white and brown gene products form a guanine transporter
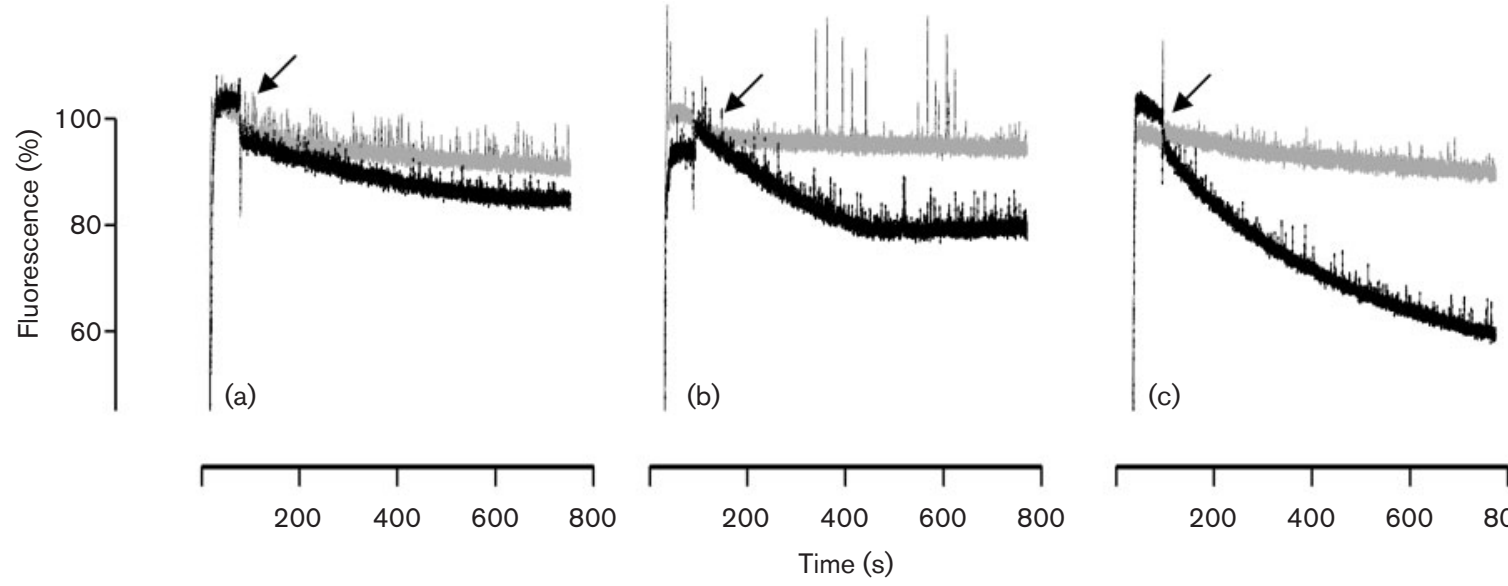

(c)

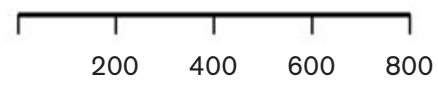

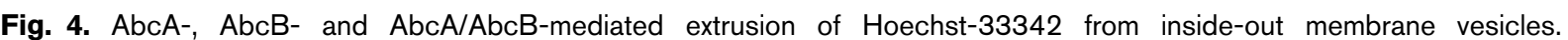
Membranes were prepared from NZ9000 cells harbouring pNAbcA (a); pNAbcB (b), or pNAbcA/pNAbcB (c). The arrow indicates the addition of $2 \mathrm{mM}$ ATP (black lines) or AMP-PNP (grey lines). Hoechst-33342 transport in L. lactis NZ9000/ pNZ8048 control membranes was not observed under the same assay conditions (data not shown). The graphics shown are representative of three independent experiments with three different batches of vesicles for each strain. 
(Mackenzie et al., 1999). In a similar way, we have observed that when $\mathrm{AbcA}$ and $\mathrm{AbcB}$ are co-expressed in L. lactis cells, $\mathrm{AbcB}$ is produced about two times more than AbcA. This implies that in $\mathrm{pNAbcA} / \mathrm{pNAbcB}$-containing cells there would be a population of free $A b c B$, not bound to $A b c A$. Since we have shown that $\mathrm{AbcB}$ alone is active under certain conditions, this could partially mask the activity of the heterodimer. Future reconstitution studies could address these questions.

In short, this study has provided evidence that $\mathrm{AbcA}$ and $\mathrm{AbcB}$ act as a heterodimeric $\mathrm{ABC}$-type multidrug transporter, conferring resistance to nisin and polymyxin and extruding cytotoxic compounds. Therefore, we propose to rename $\mathrm{AbcA}$ and $\mathrm{AbcB}$ as $\mathrm{BbmA}$ (Bifidobacterium breve multidrug transporter) and $\mathrm{BbmB}$, respectively. These findings provide the basis for further biochemical studies of $\mathrm{BbmAB}$ and the half-size transporters $\mathrm{BbmA}$ and $\mathrm{BbmB}$, and open some questions about the physiological role of this $B$. breve transporter in its natural environment, the intestinal niche.

\section{ACKNOWLEDGEMENTS}

This work was financed by the European Union STREP project ACEART (FP6-506214), European Union FEDER funds, and the Spanish Plan Nacional de I+D (project AGL2004-06727-C02). J. A. Moreno was the recipient of a post-doctoral contract from CSIC (I3P programme), Spain. The work was also financially supported by the Department of Agriculture and Food FIRM programme (01/R\&D/C/ 159), by the Higher Education Authority Programme for Research in Third Level Institutions, and by the SFI-funded Alimentary Pharmabiotic Centre. We thank S. Leahy, M. O'Connell-Motherway, G. F. Fitzgerald and H. G. Higgins for sharing unpublished data with us. We acknowledge Oscar Kuipers (Genetics Department, University of Groningen, The Netherlands) for providing us with the plasmid pNZ8048 and Daniel Linares (IPLA-CSIC) for excellent assistance in carrying out the quantitative PCR.

\section{REFERENCES}

Abele, R. \& Tampe, R. (1999). Function of the transport complex TAP in cellular immune recognition. Biochim Biophys Acta 1461, 405-419.

Begley, M., Gahan, C. G. \& Hill, C. (2005). The interaction between bacteria and bile. FEMS Microbiol Rev 29, 625-651.

Chang, G. \& Roth, C. B. (2001). Structure of MsbA from E. coli: a homolog of the multidrug resistance ATP binding cassette (ABC) transporters. Science 293, 1793-1800.

de Ruyter, P. G., Kuipers, O. P. \& de Vos, W. M. (1996). Controlled gene expression systems for Lactococcus lactis with the food-grade inducer nisin. Appl Environ Microbiol 62, 3662-3667.

Doerrler, W. T. \& Raetz, C. R. (2002). ATPase activity of the MsbA lipid flippase of Escherichia coli. J Biol Chem 277, 36697-36705.

Gajic, O., Buist, G., Kojic, M., Topisirovic, L., Kuipers, O. P. \& Kok, J. (2003). Novel mechanism of bacteriocin secretion and immunity carried out by lactococcal multidrug resistance proteins. J Biol Chem 278, 34291-34298.

Ganzle, M. G., Hertel, C., van der Vossen, J. M. \& Hammes, W. P. (1999). Effect of bacteriocin-producing lactobacilli on the survival of
Escherichia coli and Listeria in a dynamic model of the stomach and the small intestine. Int J Food Microbiol 48, 21-35.

Grkovic, S., Brown, M. H. \& Skurray, R. A. (2002). Regulation of bacterial drug export systems. Microbiol Mol Biol Rev 66, 671-701.

Hancock, R. E. \& Chapple, D. S. (1999). Peptide antibiotics. Antimicrob Agents Chemother 43, 1317-1323.

Harmsen, H. J., Wildeboer-Veloo, A. C., Raangs, G. C., Wagendorp, A. A., Klijn, L., Bindels, J. G. \& Welling, G. W. (2000). Analysis of intestinal flora development in breast-fed and formula-fed infants by using molecular identification and detection methods. $J$ Pediatr Gastroenterol Nutr 30, 61-67.

Hirata, T., Saito, A., Nishino, K., Tamura, N. \& Yamaguchi, A. (2004). Effects of efflux transporter genes on susceptibility of Escherichia coli to tigecycline (GAR-936). Antimicrob Agents Chemother 48, 2179-2184.

Isolauri, E., Salminen, S. \& Ouwehand, A. C. (2004). Microbial-gut interactions in health and disease. Probiotics. Best Pract Res Clin Gastroenterol 18, 299-313.

Karow, M. \& Georgopoulos, C. (1993). The essential Escherichia coli $m s b A$ gene, a multicopy suppressor of null mutations in the $h t r B$ gene, is related to the universally conserved family of ATP-dependent translocators. Mol Microbiol 7, 69-79.

Kim, S. H., Chang, A. B. \& Saier, M. H., Jr (2004). Sequence similarity between multidrug resistance efflux pumps of the ABC and RND superfamilies. Microbiology 150, 2493-2495.

Kok, J., Buist, G., Zomer, A. L., van Hijum, S. A. \& Kuipers, O. P. (2005). Comparative and functional genomics of lactococci. FEMS Microbiol Rev 29, 411-433.

Kuipers, O. P., Beerthuyzen, M. M., Siezen, R. J. \& de Vos, W. M. (1993). Characterization of the nisin gene cluster nisABTCIPR of Lactococcus lactis. Requirement of expression of the nisA and nisI genes for development of immunity. Eur J Biochem 216, 281-291.

Kuipers, O. P., de Ruyter, P. G., Kleerebezem, M. \& de Vos, W. M. (1998). Quorum sensing-controlled gene expression in lactic acid bacteria. J Biotechnol 64, 15-21.

Lee, E. W., Huda, M. N., Kuroda, T., Mizushima, T. \& Tsuchiya, T. (2003). EfrAB, an ABC multidrug efflux pump in Enterococcus faecalis. Antimicrob Agents Chemother 47, 3733-3738.

Liu, L. X., Janvier, K., Berteaux-Lecellier, V., Cartier, N., Benarous, R. \& Aubourg, P. (1999). Homo- and heterodimerization of peroxisomal ATP-binding cassette half-transporters. J Biol Chem 274, 32738-32743.

Lubelski, J., Mazurkiewicz, P., van Merkerk, R., Konings, W. N. \& Driessen, A. J. (2004), $y d a G$ and $y d b A$ of Lactococcus lactis encode a heterodimeric ATP-binding cassette-type multidrug transporter. J Biol Chem 279, 34449-34455.

MacConaill, L. E., Butler, D., O'Connell-Motherway, M., Fitzgerald, G. F. \& van Sinderen, D. (2003). Identification of two-component regulatory systems in Bifidobacterium infantis by functional complementation and degenerate PCR approaches. Appl Environ Microbiol 69, 4219-4226.

Mackenzie, S. M., Brooker, M. R., Gill, T. R., Cox, G. B., Howells, A. J. \& Ewart, G. D. (1999). Mutations in the white gene of Drosophila melanogaster affecting $\mathrm{ABC}$ transporters that determine eye colouration. Biochim Biophys Acta 1419, 173-185.

Mahida, Y. R., Rose, F. \& Chan, W. C. (1997). Antimicrobial peptides in the gastrointestinal tract. Gut 40, 161-163.

Margolles, A. \& de los Reyes-Gavilán, C. G. (2003). Purification and functional characterization of a novel $\alpha$-L-arabinofuranosidase from Bifidobacterium longum NB667. Appl Environ Microbiol 69, 5096-5103.

Margolles, A., Putman, M., van Veen, H. W. \& Konings, W. N. (1999). The purified and functionally reconstituted multidrug transporter 
LmrA of Lactococcus lactis mediates the transbilayer movement of specific fluorescent phospholipids. Biochemistry 38, 16298-16306.

Margolles, A., Moreno, J. A., van Sinderen, D. \& de los Reyes-Gavilan, C. G. (2005). Macrolide resistance mediated by a Bifidobacterium breve membrane protein. Antimicrob Agents Chemother 49, 4379-4381.

Matsuki, T., Watanabe, K., Tanaka, R., Fukuda, M. \& Oyaizu, H. (1999). Distribution of bifidobacterial species in human intestinal microflora examined with 16S rRNA gene-targeted species-specific primers. Appl Environ Microbiol 65, 4506-4512.

Mazurkiewicz, P., Driessen, A. J. \& Konings, W. N. (2005). What do proton motive force driven multidrug resistance transporters have in common? Curr Issues Mol Biol 7, 7-21.

Moubareck, C., Gavini, F., Vaugien, L., Butel, M. J. \& DoucetPopulaie, F. (2005). Antimicrobial susceptibility of bifidobacteria. $J$ Antimicrob Chemother 55, 38-44.

Orelle, C., Dalmas, O., Gros, P., di Pietro, A. \& Jault, J. M. (2003). The conserved glutamate residue adjacent to the Walker-B motif is the catalytic base for ATP hydrolysis in the ATP-binding cassette transporter BmrA. J Biol Chem 278, 47002-47008.

Ouwehand, A. C., Salminen, S. \& Isolauri, E. (2002). Probiotics: an overview of beneficial effects. Antonie Van Leeuwenhoek 82, 279-289.

Price, C. E., Reid, S. J., Driessen, A. J. \& Abratt, V. R. (2006). The Bifidobacterium longum NCIMB $702259^{\mathrm{T}}$ ctr gene codes for a novel cholate transporter. Appl Environ Microbiol 72, 923-926.

Putman, M., van Veen, H. W. \& Konings, W. N. (2000). Molecular properties of bacterial multidrug transporters. Microbiol Mol Biol Rev 64, 672-693.

Raherison, S., González, P., Renaudin, H., Charron, A., Bebear, C. \& Bebear, C. M. (2005). Increased expression of two multidrug transporter-like genes is associated with ethidium bromide and ciprofloxacin resistance in Mycoplasma hominis. Antimicrob Agents Chemother 49, 421-424.

Ravaud, S., do Cao, M. A., Jidenko, M., Ebel, C., le Maire, M., Jault, M., di Pietro, A., Haser, R. \& Aghajari, N. (2006). The ABC transporter BmrA from Bacillus subtilis is a functional dimer in the detergent-solubilized state. Biochem J 395, 345-353.

Sakamoto, K., Margolles, A., van Veen, H. W. \& Konings, W. N. (2001). Hop resistance in the beer spoilage bacterium Lactobacillus brevis is mediated by the ATP-binding cassette multidrug transporter HorA. J Bacteriol 183, 5371-5375.

Salminen, S. \& Gueimonde, M. (2004). Human studies on probiotics: what is scientifically proven? J Food Sci 69, 137-140.
Sambrook, J., Fritsch, E. F. \& Maniatis, T. (1989). Molecular Cloning: a Laboratory Manual, 2nd edn. Cold Spring Harbor, NY: Cold Spring Harbor Laboratory.

Schneider, E. \& Hunke, S. (1998). ATP-binding-cassette (ABC) transport systems: functional and structural aspects of the ATPhydrolyzing subunits/domains. FEMS Microbiol Rev 22, 1-20.

Shapiro, A. B. \& Ling, V. (1995). Reconstitution of drug transport by purified P-glycoprotein. J Biol Chem 270, 16167-16175.

Turnbull, P. C., Sirianni, N. M., LeBron, C. I., Samaan, M. N., Sutton, F. N., Reyes, A. E. \& Peruski, L. F. (2004). MICs of selected antibiotics for Bacillus anthracis, Bacillus cereus, Bacillus thuringiensis, and Bacillus mycoides from a range of clinical and environmental sources as determined by the Etest. J Clin Microbiol 42, 3626-3634.

van Veen, H. W., Venema, K., Bolhuis, H., Oussenko, I., Kok, J., Poolman, B., Driessen, A. J. \& Konings, W. N. (1996). Multidrug resistance mediated by a bacterial homolog of the human multidrug transporter MDR1. Proc Natl Acad Sci U S A 93, 10668-10672.

van Veen, H. W., Margolles, A., Muller, M., Higgins, C. F. \& Konings, W. N. (2000). The homodimeric ATP-binding cassette transporter LmrA mediates multidrug transport by an alternating two-site (twocylinder engine) mechanism. EMBO J 19, 2503-2514.

Vedantam, G. \& Hecht, D. W. (2003). Antibiotics and anaerobes of gut origin. Curr Opin Microbiol 6, 457-461.

Ventura, M., van Sinderen, D., Fitzgerald, G. F. \& Zink, R. (2004). Insights into the taxonomy, genetics and physiology of bifidobacteria. Antonie van Leeuwenhoek 86, 205-223.

Walker, J. E., Saraste, M., Runswick, M. J. \& Gay, N. J. (1982). Distantly related sequences in the $\alpha$ - and $\beta$-subunits of ATP synthase, myosin, kinases and other ATP-requiring enzymes and a common nucleotide binding fold. EMBO J 1, 945-951.

Woebking, B., Reuter, G., Shilling, R. A., Velamakanni, S., Shahi, S., Venter, H., Balakrishnan, L. \& van Veen, H. W. (2005). Drug-lipid A interactions on the Escherichia coli ABC transporter MsbA. J Bacteriol 187, 6363-6369.

Yokota, A., Veenstra, M., Kurdi, P., van Veen, H. W. \& Konings, W. N. (2000). Cholate resistance in Lactococcus lactis is mediated by an ATP-dependent multispecific organic anion transporter. J Bacteriol 182, 5196-5201.

Zúñiga, M., Franke-Fayard, B., Venema, G., Kok, J. \& Nauta, A. (2002). Characterization of the putative replisome organizer of the lactococcal bacteriophage r1t. J Virol 76, 10234-10244. 